\title{
Waste from livestock and poultry breeding and its potential assessment of biogas energy in rural China
}

\author{
Fei Li ${ }^{a,}{ }^{*}$, Shengkui Cheng ${ }^{a}$, Huilu Yu ${ }^{a}$, Dewei Yang ${ }^{b}$ \\ a Institute of Geographic Sciences and Natural Resources Research, Chinese Academy of Sciences, Beijing, 100101, China \\ ${ }^{\mathrm{b}}$ Key Lab of Urban Environment and Health, Institute of Urban Environment, Chinese Academy of Sciences, Xiamen, 361021, China
}

\section{A R T I C L E I N F O}

\section{Article history:}

Received 9 May 2015

Received in revised form

22 February 2016

Accepted 24 February 2016

Available online 7 March 2016

\section{Keywords:}

Waste from livestock and poultry breeding Rural energy

Environmental Kuznets curve

Biogas

China

\begin{abstract}
A B S T R A C T
Global livestock and poultry industry is growing continuously, with large amounts of excreta produced. These wastes could be either important anaerobic fermentation materials of biogas energy or, if discharged into the environment without appropriate processing, serious pollution sources to soil and water systems. In developing countries, rural energy poverty is currently a major threat to sustainable development and livelihoods. Hence, the availability of clean, affordable and reliable energy is of significant concern in both policy and scholarly circles. Moreover, pollutants related with animal husbandry have been identified as one of the dominant contributors to contamination of water systems, such as surface water eutrophication and groundwater nitrate enrichment. Consequently, assessing waste from livestock and poultry breeding and the associated biogas systems is of critical essence in rural energy and environmental decision-making. The present study concentrates on a Chinese context and attempts to explicitly investigate Environmental Kuznets Curve (EKC) applying heterogeneous panel cointegration methods, combining with distribution and characteristics of waste from livestock and poultry breeding for China's 31 provincial economies from 1991 to 2013. And, potentiality of biogas energy and its $\mathrm{CO}_{2}$ emission reduction based on the utilization of waste is assessed. The empirical results indicate an inverted U-shaped Environmental Kuznets Curve in $\mathrm{N}$ indicator resulting from livestock and poultry breeding, where value of the turning point is approximately CNY 51,800. With economic growth and consumptive change, problems arising from animal husbandry mode can be increasingly great. There will be many major challenges to address these special environmental issues in rural area, especially in Central China and West China. Biogas production by animal excreta could be one of the most important rural energies and waste treatment patterns, which could reach 63.65 billion $\mathrm{m}^{3}$ in 2013 , equivalent to approximately $20 \%$ of natural gas used, and might offer a GHG reduction of more than 220 million tons of $\mathrm{CO}_{2}$ eq. China should assign greater importance to special agricultural pollution and energy options in rural communities, in addition to 'beautiful countryside' propaganda.
\end{abstract}

(c) 2016 Elsevier Ltd. All rights reserved.

\section{Introduction}

The increase in pollutants driven by agriculture, especially animal husbandry, has cascading consequences for the environment and human health, including degradation of air and water quality and also increases in the pressures of disease and pest (Townsend et al., 2003; Bouwman et al., 2009; MacDonald et al., 2011; Schipanski and Bennett, 2012). Over the past decades, annual

\footnotetext{
* Corresponding author. Institute of Geographic Sciences and Natural Resources Research, Chinese Academy of Sciences, 11A, Datun Road, Beijing 100101, China. Tel.: +(86) 1064889527.

E-mail address: lifcas@gmail.com (F. Li).
}

global meat consumption per capita has nearly doubled. Wastes from livestock and poultry breeding are increasingly concentrated in confined animal feeding operations, far from areas of intensive crop farming where the excreta could be used as fertilizer, which are largely either spread on fields as dry litter or pumped into waste lagoons and sprayed as liquid onto fields (Mallin and Cahoon, 2003; Schipanski and Bennett, 2012). This has been identified as one of the dominant contributors to contamination of water systems globally, such as surface water eutrophication and groundwater nitrate enrichment (DEFRA, 2004; EEA, 2005; USEPA, 2009), especially in some developing countries (Gerber et al., 2005; Chen et al., 2010). 
China has experienced a tremendous economic growth since the market opened up in the early 1990s, with increasingly rapid process of urbanization and industrialization. However, China can still be considered an 'agricultural country', with over $65 \%$ of the national population registered as agricultural households. And, China's rural year-end population proportion is more than $50 \%$, even when excluding peasant workers statistically. The substantial urban-rural gap still widely exists within the context of economy, society and culture. Pollution from agriculture and rural area has become one of the most prominent environmental problems due to lack of proper treatment in China, even though urban and industrial pollution can be monitored and managed more efficiently.

Under industrializing and urbanizing demand, the China's economy witnessed a rapid growth of animal husbandry. In 2013, the year-end number of hogs and poultry stocks reached 0.47 and 5.71 billion, respectively, whereas the number of slaughtered hogs and poultry was 0.72 and 11.9 billion, respectively. China's output of meat has been ranking first place globally for more than 20 years. However, due to extensive production mode and lack of waste treatment facilities, a large amount of sewage from animal husbandry has generally been discharged directly into the environment. This is severely polluting the air, land and water systems (CCICED, 2009). As shown in the First National Pollution Source Census Bulletin (P. R. China) (MEP, 2010), agriculture-related emission of Chemical Oxygen Demand (COD), Nitrogen (N) and Phosphorus $(\mathrm{P})$ was $13.2409,2.7046$ and 0.2847 million tons, accounting for $41.9 \%, 21.7 \%$ and $37.9 \%$ of total national pollutants, respectively. And Emission of COD, N and P from livestock and poultry breeding reached $12.6826,1.0248$ and 0.1604 million tons, respectively. Moreover, the number of statistical agriculture-related pollution sources is only 2.899 million. In 2010, emission of COD and $\mathrm{NH}_{3}-\mathrm{N}$ from livestock and poultry breeding reached 11.48 and 0.65 million tons, which was 3.23 and 2.30 times that from industrial sources, with the percentage of $45 \%$ and $25 \%$ of the total national pollutants, respectively (NBS and MEP, 2011).

In addition, China's growth is fuelling rapid increases in energy demand across all sectors. In the context of rural energy, this demand brings the associated environmental challenges such as air quality, forest conservation and GHG issues (Christiaensen and Heltberg, 2012). Rural energy is not a traditional concept in most energy catalogues. It mainly refers to energy problems of rural areas in developing countries, as many farmers have to rely on local crude energy due to shortage of commercial energy and backward economies (CCICED, 2009). In many developing countries, a huge portion of the population (over 2.6 billion people) are relying primarily on traditional biomass, over $80 \%$ of who are living in rural areas (IEA, 2013) and negatively affected as the lack of access to clean, affordable and reliable energy. Providing sustainable energy services has been acknowledged as a key component to reduce poverty and improve their livelihoods (IEA, 2013). In China, over $85 \%$ of the population without access to clean fuels are located in rural areas (Fan et al., 2011), where various socio-economic conditions make energy issues much more complicated than in urban areas. Moreover, China's rural household is the basic and main pattern of agricultural activities. With insufficient energy consumption per capita (50\% less than national average), they have been using traditional and non-commercial energy for a long history (over $76.8 \%$ of total energy use) (Fan et al., 2011), such like firewood and straw as their main energy sources for nonproduction purposes on a large scale, although many rural households were provided with access to commercial coal (62.6\% of the household commercial energy) (SCIO, 2007; Fan et al., 2011) and electricity by extension of power grids and the small hydropower exploitation. Despite recent research progress and policy developments in the field of China's rural energy (Li et al., 2014), most of them are still only some universal ideas of the rural energy presented. Exploration of specific and effective approaches to rural energy based on the energy materials estimation, and analytics of energy and emission reduction options to these rural communities, is still a major study point of criticism and key policy issue in many developing countries.

Over the last decades, global livestock and poultry industry is growing continuously, with large amounts of excreta produced. Significantly, these wastes could be either important materials of biogas energy or, if discharged into the environment without appropriate processing, a serious pollution source to soil and water systems, which has received increased attention among environmentalists, economists and policymakers. Identifying quantitative information is critically essential to focus and advance the decisionmaking debate, especially in the context of developing countries. Hence, it might have promising implications for sustainability to assess the impact of animal husbandry on the environment and biogas energy potential stemming from the excreta in rural areas. Several studies provided evidences of the management effectiveness in reducing sediments and nutrients contained in runoff (Chaubey et al., 1995; Rodriguez et al., 2011). However, the general substantial explorations and effective options are not as put forward as could be in developing countries, including China, although recently case study progress has emerged in controlling water pollution or promoting biogas, especially in some nutrient-surplus areas around the world (Ding et al., 2012; Dai et al., 2015). Several recent studies involved carbon emission of rural energy in China (Li et al., 2014), but overlooking the biogas energy related with livestock and poultry breeding. An assessment of wastes from livestock and poultry breeding and the associated crucial environmental and energy policy remain scarce in China. Hence, combining with the distribution and characteristics of China's rural wastes from livestock and poultry breeding, approach to the Environmental Kuznets Curve (EKC) is performed using heterogeneous panel cointegration methods. To the best of the authors' knowledge, none of prior studies tested the EKC with regard to this particular rural environmental issue on such a scale of developing country as China's, although there are an abundance of studies on air or water pollution and deforestation (Li et al., 2016). Besides, the present study assesses the potentiality of biogas energy and the $\mathrm{CO}_{2}$ emission reduction related with utilization of animal wastes, before finally offering a policy discussion on some rural energy options.

\section{Methodology}

\subsection{Estimation method of wastes from livestock and poultry breeding}

We firstly studied the impacts of livestock and poultry breeding within the framework of environment and development initiatives. Over the recent decades, literature of human impacts on global biogeochemical cycles largely focused upon nitrogen (Vitousek et al., 1997; Galloway et al., 2003; Schipanski and Bennett, 2012). The amount of excreta and the nitrogen masses are chosen as main environmental indicators on the basis of China's spatial livestock and poultry number and estimated excretion values (Gerber et al., 2005; Gao et al., 2006; Wang et al., 2011). In China, current waste estimation methods are in line with daily emission and annual emission as follows:

$P=\sum_{i=1}^{n} Q_{i} \times W_{i} \times P d_{i} \times T_{i}$ 
$P=\sum_{i=1}^{n} Q_{i} \times P a_{i}$

where $P$ denotes the annual pollutant emissions from livestock and poultry breeding. $Q_{i}$ is the amount of livestock and poultry and $W_{i}$ is the daily waste production for animal type $i . P d_{i}$ stands for the pollutant coefficient of waste and $T_{i}$ is the growth period for animal type $i . P a_{i}$ stands for the annual emissions of pollutants for animal type $i$. Livestock and poultry mainly involve cattle, hogs, sheep, rabbits, chicken, ducks and other main animal types.

The growth period of livestock is commonly taken as being over one year and that of poultry is calculated according to actual breeding days, which totals about 55 days, 210 days and one year for broilers, ducks and geese, and layers, respectively. The levels of pollution from animal production can vary across species, farm scales, breeding means, climate and other determinants. The estimation method by annual emission is more feasible with regards to conducting the actual calculation and dealing with manageable data volumes. And the amount of nutrients released from excreta to water body can be estimated according to the average waste release rate (Gao et al., 2006; Wang et al., 2011). The emission coefficients of livestock and poultry are presented in Table 1 as below. The number of poultry and hog is calculated based on quantity slaughtered, while that of livestock in line with year-end number of stock, accounting for different growth periods.

Agricultural land is the main disposal site for excreta from animal husbandry, which involves cultivated land and mowing land. Nutrient loads per unit of agricultural land can stand for the risk of pollution from livestock and poultry breeding (Gao et al., 2006; Wang et al., 2011). It can be calculated as follows:

$L_{N}=N / A$

where $L_{N}$ is the nutrient loads per unit of agricultural land accounting for animal husbandry. $N$ denotes amount of nutrients from animal wastes, and $A$ is area of agricultural land.

The data of livestock and poultry breeding and agricultural land are available in the Chinese Statistical Yearbooks and the Chinese Rural Statistical Yearbooks. The sample includes Beijing, Tianjin, Hebei, Shanxi, Inner Mongolia, Liaoning, Jilin, Heilongjiang, Shanghai, Jiangsu, Zhejiang, Anhui, Fujian, Jiangxi, Shandong, Henan, Hubei, Hunan, Guangdong, Guangxi, Hainan, Chongqing, Sichuan, Guizhou, Yunnan, Shaanxi, Gansu, Qinghai, Ningxia, Xinjiang and Tibet. Chongqing is seen as a part of Sichuan province in this study, as it was upgraded to a municipality (provincial level) in the late 1990s.

\subsection{Environmental Kuznets Curve}

The Environmental Kuznets Curve, as the classic theory on the relationship between environmental pollution and economic growth, has been studied by many researchers using various

Table 1

Coefficients of pollutant emission from livestock and poultry ${ }^{\mathrm{a}}(\mathrm{kg} / \mathrm{head} \bullet \mathrm{a})$.

\begin{tabular}{lcccc}
\hline & Manure & Urine & $\mathrm{N}$ & COD \\
\hline Cattle and Buffaloes & 7300 & 3650 & 61.1 & 848.2 \\
Hogs & 1367.6 & 1701.9 & 11.5 & 36 \\
Sheep and Goats & 474 & 158 & 5.8 & 4.4 \\
Poultry & 32.03 & - & 0.4 & 1.765 \\
Rabbit & 45 & 25 & 0.7 & - \\
\hline
\end{tabular}

a Sourced from literatures (Jin, 1995; CNATE, 1999; SEPA, 2002; Gao et al., 2006: Qu, 2007; Wang et al., 2011). methodologies for different periods since becoming a key topic, following the pioneering work of Grossman and Krueger (1991, 1995) and Panayotou (1993), where the inverted U-shaped curve was found. This relationship has become the focus of a large number of theoretical explorations and empirical investigations in many countries, based mainly on the empirical estimation of time series and the dynamic panel data approach (Brock and Taylor, 2005; Li et al., 2016). The studies of Dasgupta et al. (2002), Stern (2004), Dinda (2004), Brock and Taylor (2005), Carson (2010), Chowdhury and Moran (2012) and de Ribeiro and Kruglianskas, 2015 among others, provide extensive review surveys of the literature which tested the economic growth-environmental pollution nexus and the EKC hypothesis. There is an increasing progress of researches on air or water pollution, deforestation, diversity and indicators of environmental amenities up until for some recent findings around the world (e. g. Kaika and Zervas, 2013; Katz, 2015; Wang et al., 2015, 2016a), also in China (e. g. Xu and Lin, 2015; Yao et al., 2016; Hao and Liu, 2016; Wang et al., 2016b). However, researches on the relationship between agriculture-related pollution and economic growth are relatively scanty (Shortle and Abler, 2001; Aftab et al., 2010), few of which were related to Environmental Kuznets Curve. To our knowledge, few other prior studies have tested the EKC in the case of these environmental issues arising from livestock and poultry breeding. This issue is significant considering the importance of environmental and ecological safety issues (Shortle and Abler, 2001), and should be taken more attention. No sole environment-economy relationship exists that fits all types of pollutants, regions scales and time periods. Hence, several key issues require urgent research and resolution. For example, is there an inverted U-shaped EKC for environmental issues resulting from livestock and poultry breeding in China? How can this animal husbandry related environmental-growth nexus be interpreted? What is the potential of rural energy materials by animal excreta?

Based on the perspective of environment-economy nexus, agriculture related pollution can be regarded as a contradiction between economic growth and environment and resources, which is essentially the discrepancy between the infinite demand from economic growth on agro-resources and the limited supply capacity of the environment. Waste from livestock and poultry breeding is a negative externality of agricultural production in nature. In addition, as a result of urban-rural dual structure, property rights, and other institutional factors, there is an agriculturerelated environmental regulation failure. Economic growth has thus a double impact on the quality of the environment, and intricately agriculture-related environmental issues significantly influence economic growth. Intertwined with increased urbanization and industrialization, rapid economic growth can exert considerable influences on the agriculture-related environmental issues as to some economic effects. There are some main theoretical explanations supporting the empirical evidence that an EKC exists. Each of the following explanations could interact with the others (Galeotti et al., 2009; Li et al., 2016).

Firstly, economic growth exhibits a scale effect that has a negative impact on the environment in the early stages of development (Copeland and Taylor, 2004). With rising economic growth, the demand for agricultural products, especially meat, egg and milk, is increasing largely in China, while man-earth conflict becomes intensifying. However, as income grows in the later stages of development, there is an increase in cleaner activities that produce less pollution. Whether policies are socially efficient or not, EKC can exist because of increasing returns to scale (Andreoni and Levinson, 2001).

Secondly, income effects, where the shape of the EKC reflects changes in the demand for environmental quality, or agri-risk in this study, as income rises. Economic development can transform 
Table 2

Indices of pollution and economic growth.

\begin{tabular}{lll}
\hline Index & Unit & Abbreviation of index \\
\hline GDP per capita & CNY & GDP \\
Share of agricultural output in GDP & $\%$ & AO \\
Nitrogen emission from livestock and poultry breeding & ton & $\mathrm{N}$ \\
\hline
\end{tabular}

agriculture-related environmental quality into a consumer utility function, and the market demand constraints induce progressive agricultural producers and government more attention to the environmental concerns. Moreover, economic growth will improve the national education level and environmental awareness of farmers significantly.

Thirdly, threshold effects. An environmental measure is implemented after the threshold has been reached. These effects can arise in either the abatement opportunities (Stokey, 1998), or in the political process (Jones and Manuelli, 2001). The first type of threshold effects is related to the technology constraint explanation (Israel and Levinson, 2004). A strong economic base could provide for the application of environmentally-friendly technologies and the skill mastering of farmers. The second type of threshold effects refers to an institutional or policy constraint explanation. In China, agriculture is mainly characterized at present by the traditional production mode based on the single farmer household unit. And the dual social structure is more prominent than other similar countries under transformation. Rural environmental protection is consequently neglected, wherein the supply of environmental policies, environmental agencies, and environmental infrastructure is highly insufficient. Agricultural pollution issue can be regarded as a by-product of the special urban-rural dualistic structure and accordingly becomes a both extension and aggravation of the social structure and equity issues in China.

In this study, a standard EKC model is expressed as a logarithmic quadratic function of income to examine whether or not an inverted U-shaped EKC relationship between the pollution and economic growth exists. Then, the homogeneous EKC model is usually given as in Stern (Stern, 2003, 2010):

$E_{i t}=\alpha+\beta_{1} Y_{i t}+\beta_{2} Y_{i t}^{2}+\theta_{i t}$

where $E$ refers to environmental effects, e.g. nitrogen emissions from livestock and poultry breeding, and $Y$ denotes economic growth. The subscript $i$ stands for a provincial index $(i=1, \ldots, 31)$ and $t$ is a time index $(t=1, \ldots, 23)$. $\theta_{i t}$ is a stochastic error term that is generally allowed to be serially correlated. The share of agricultural output in GDP is also taken as an explanatory variable. Table 2 shows the indices of pollution from livestock and poultry breeding and economic growth.

\subsection{Econometric methods}

In view of data availability, we select 23-year panel data from 1991 to 2013 covering 31 provincial economies in China as our study samples. To ensure the comparability of data, we deflate the raw data at current prices to comparable price series. The relatively small time series samples for each province necessitate using panel methods to improve the power of the tests. Thus, we use heterogeneous panel cointegration technique to investigate the inverted U-shaped EKC hypothesis and estimate the cointegration vector for heterogeneous cointegrated panels using the dynamic ordinary least squares (DOLS) technique. Contrary to the EKC literature involving cross-country comparisons, an inter-provincial research is undertaken because using provincial-level data may make it safer to assume that all cross-sections adhere to the same EKC, i.e. it may not be reasonable to impose isomorphic EKCs if cross-sections vary much in terms of a certain endowments (Unruh and Moomaw, 1998; Managi, 2006; Li et al., 2016). Hereinafter, unit root properties of the panel data are properly examined firstly, adopting three different methods, namely those of Levine et al. (2002), Im et al. (2003) and Maddala and Wu (1999), i.e. the LLC, IPS and the Fisher-ADF and Fisher-PP statistics, respectively. Second, the existence of a cointegration relationship between livestock and poultry pollution and economy variables is tested using the panel cointegration technology developed firstly by Pedroni (1997, 2000, 2004). Finally, the ordinary least squares and dynamic ordinary least squares estimators proposed first by Kao and Chiang (2000) and McCoskey and Kao $(1999,2001)$ are used to evaluate long-run relationship among the considered variables.

\section{Results}

\subsection{Assessment of wastes from livestock and poultry breeding}

The amount of waste from livestock and poultry breeding calculated is approximately twice as large as that of industrial solid wastes produced in China, based on the estimation method of annual emissions. $\mathrm{N}$ from animal husbandry reached around 21.31 million tons in 2013, an estimate that is over twice the number produced in 1991. And the average annual output from 1991 to 2013, considered in this study, reached more than 19 million tons. Besides, China's national nitrogen fertilizer consumption was only over 23.94 million tons in 2013 . On the whole, $\mathrm{N}$ excreted by livestock and poultry breeding is mostly distributed in Middle China, South China and Southwest China, especially in the areas of Hunan, Shandong, Henan and Sichuan, at around 1.15, 1.72, 1.73 and 1.79 million tons, respectively.

Then, the study examined the excreta pollution risk of agricultural land arising from livestock and poultry breeding in various provinces, based on land use data from 2003 to 2008 released by China's Ministry of Land and Resources. ${ }^{1}$ Considering cultivated land and mowing land, the national nutrient loads per unit of agricultural land related to animal husbandry reached around $46.5 \mathrm{~kg} /$ hectare in 2008. The respective value for Beijing, Tianjin, Liaoning, Guangdong, Hainan and others exceeded that in other provinces, and has far went beyond the Europe Union safety standard cordon of only $170 \mathrm{~kg} /$ hectare designed to prevent pollution for soil and water systems ${ }^{2}$ (see Figs. 1 and 2). In addition, considering chemical fertilizer use, only the nitrogen fertilizer consumption per hectare of cultivated land reached more than $180 \mathrm{~kg} /$ hectare in 2008. Due to its low efficiency and extensive mode of agricultural production, China is confronted with some serious challenges in trying to address specifically the pollution issues from livestock and poultry breeding with domestic socioeconomic transition.

\footnotetext{
${ }^{1}$ China's agricultural land use data are available from 2003 to 2008.

2 The nutrient standard for preventing pollution from animal husbandry is still not enacted in China.
} 


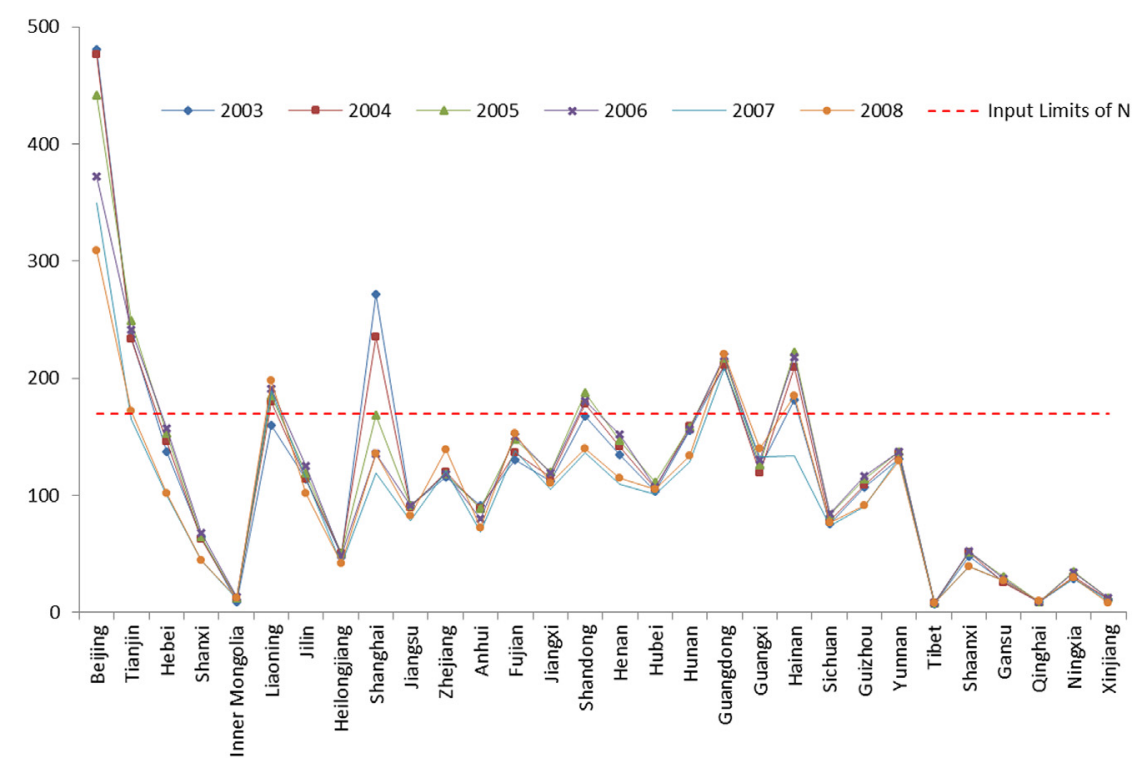

Fig. 1. N loads per unit of agricultural land from livestock and poultry breeding from 2003 to 2008 ( $\mathrm{kg} / \mathrm{hectare}$ ).

\subsection{EKC approach}

In this section, we report the estimation results of the EKC investigating the relationship between livestock and poultry breeding related pollution and economic growth. The empirical findings derived using the above econometric methods will be presented as below.

Before conducting the cointegration analysis of the panel data, the panel unit root test is firstly conducted. Table 3 shows the panel unit root test results. The statistics confirm that the series of variables are I (1) process wholly.

Furthermore, we proceed to test pollution and economy variables, respectively, for cointegration in the data using the heterogeneous panel cointegration test. The Panel ADF-statistic, group ADF-statistic, Panel PP-statistic and Group PP-statistic all strongly reject the null of no cointegration at $1 \%$ significance critical values (see Table 4). Accordingly, we generally obtain the evidence that livestock and poultry related pollution and economy variables tested move together in the long-run. Thus, a steady-state relationship can be signified to exist between the considered variables.

Table 5 provides the EKC results for the panel OLS and the panel DOLS tests. A panel data model with fixed effects (including both individual and time specific effects) is adopted finally. The DOLS estimators are designed for non-stationary panels. And they have a normal asymptotic distribution to control for endogeneity and to calculate standard deviations using a covariance matrix of errors that is robust to serial correlation, which outperform OLS ones and have a higher performance in terms of model fit. The values of the DOLS estimators are determined under the assumption of one lead, one lag; two leads, two lags; and others in changes of regressors. The results indicate the presence of an inverted U-shaped curve relationship between $\mathrm{N}$ and GDP per capita. In general, an economy is associated with lower pollution levels after a threshold income point in the light of EKC type. Accordingly, the value of turning

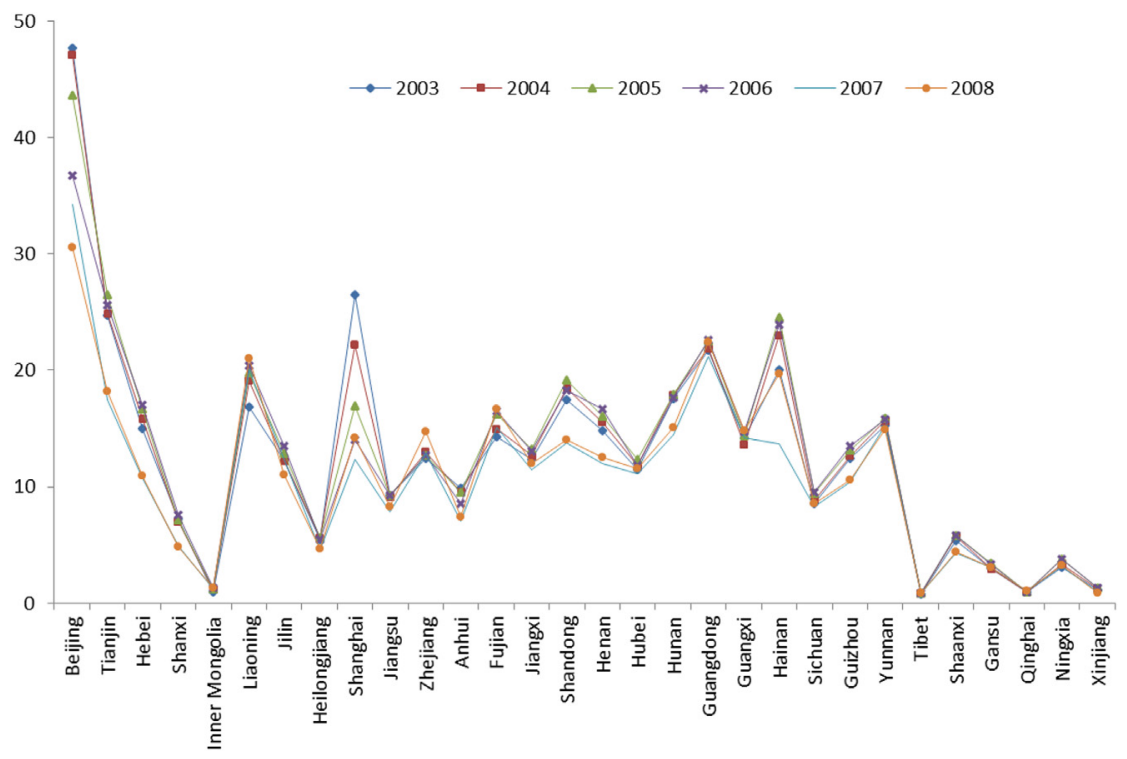

Fig. 2. Manure loads per unit of agricultural land from livestock and poultry breeding from 2003 to 2008 (kg/hectare). 
Table 3

Panel unit root test results.

\begin{tabular}{|c|c|c|c|c|c|c|}
\hline & $\mathrm{N}$ & $\mathrm{N}$ & $\mathrm{D}(\mathrm{N})^{\mathrm{a}}$ & $\mathrm{D}(\mathrm{N})$ & GDP & GDP \\
\hline & $\begin{array}{l}\text { Individual } \\
\text { effects }\end{array}$ & $\begin{array}{l}\text { Individual effects } \\
\text { and linear trends }\end{array}$ & $\begin{array}{l}\text { Individual } \\
\text { effects }\end{array}$ & $\begin{array}{l}\text { Individual effects } \\
\text { and linear trends }\end{array}$ & $\begin{array}{l}\text { Individual } \\
\text { effects }\end{array}$ & $\begin{array}{l}\text { Individual effects } \\
\text { and linear trends }\end{array}$ \\
\hline LLC $^{\mathrm{b}}$ & $-5.71^{* * * \mathrm{c}}$ & -0.02 & $-10.01^{* * *}$ & $-8.93^{* * *}$ & 2.64 & 4.19 \\
\hline IPS & $-2.01^{*}$ & 3.74 & $-6.92^{* * *}$ & $-2.57^{* * *}$ & 8.20 & 3.02 \\
\hline Fisher-ADF & 85.11 & 31.03 & $156.75^{* * *}$ & $152.68^{* * *}$ & 13.01 & 36.03 \\
\hline \multirow[t]{3}{*}{ Fisher-PP } & $148.32^{* * *}$ & 47.88 & $275.22^{* * *}$ & $307.91^{* * *}$ & 13.47 & 35.49 \\
\hline & $\mathrm{D}(\mathrm{GDP})$ & $\mathrm{D}(\mathrm{GDP})$ & $\mathrm{GDP}^{2}$ & $\mathrm{GDP}^{2}$ & $\mathrm{D}\left(\mathrm{GDP}^{2}\right)$ & $\mathrm{D}\left(\mathrm{GDP}^{2}\right)$ \\
\hline & Individual effects & $\begin{array}{l}\text { Individual effects } \\
\text { and linear trends }\end{array}$ & Individual effects & $\begin{array}{l}\text { Individual effects } \\
\text { and linear trends }\end{array}$ & Individual effects & $\begin{array}{l}\text { Individual effects } \\
\text { and linear trends }\end{array}$ \\
\hline LLC $^{\mathrm{b}}$ & $-3.31^{* * *}$ & $-10.24^{* * *}$ & 4.61 & 6.55 & $-3.40^{* * *}$ & $-9.68^{* * *}$ \\
\hline IPS & $-5.03^{* * *}$ & $-7.31^{* * *}$ & 10.26 & 4.96 & $-4.62^{* * *}$ & $-6.85^{* * *}$ \\
\hline Fisher-ADF & $127.29^{* * *}$ & $169.21^{* * *}$ & 9.69 & 26.61 & $120.10^{* * *}$ & $160.41^{* * *}$ \\
\hline Fisher-PP & $272.47^{* * *}$ & $216.51^{* * *}$ & 9.59 & 28.66 & $249.11^{* * *}$ & $206.32^{* * *}$ \\
\hline
\end{tabular}

a $\mathrm{D}$ denotes first difference.

b LLC and IPS represent the panel unit root tests of Levin et al. (2002) and Im et al. (2003), respectively. Fisher-ADF and Fisher-PP represent the Maddala and Wu (1999)

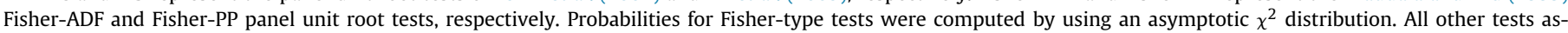
sume asymptotic normality.

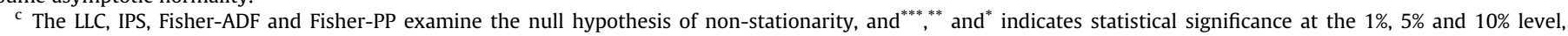
respectively.

point as calculated with the parameters is approximately CNY 51,800 (around 8,360, 2013USD) for this inverted-U shaped EKC.

\subsection{Potential assessment of biogas energy by waste from animal husbandry}

Biogas production efficiency by animal excreta is of critical essence for waste treatment, as one of the most important available energies in rural China. It is dependent on many various determinants, such as anaerobic environment, organic matter, temperature, and $\mathrm{pH}$, related to different excreta types of livestock and poultry, and other institutional and socioeconomic constraints (Zhang et al., 2008). This potential of biogas production in China can be estimated based on amount of COD or TS by animal excreta:

$P E=Q_{C O D} \times D \times C b$

where $P E$ denotes the biogas potential by wastes from livestock and poultry breeding. $Q_{C O D}$ is the amount of COD produced, and $D$ is the available percentage of COD disposed, taken as 80\% (MEP, 2010). $C b$ is the coefficient of biogas production, taken as $0.269,0.538$ and $0.807 \mathrm{~m}^{3} / \mathrm{kg}$, in the region $\left({ }^{\circ} 15^{\circ} \mathrm{C}\right)$, region $\left(15-25^{\circ} \mathrm{C}\right)$ and region $\left(>25{ }^{\circ} \mathrm{C}\right)$, respectively, according to various climate areas in China (Song et al., 2010; Tian, 2012).

Based on Equation (5), the results indicate that the output of biogas by animal excreta could reach 63.65 billion $\mathrm{m}^{3}$ in 2013 , amounting to over 45.45 million tons of SCE, which was equivalent to approximately $20 \%$ of national natural gas use in 2013 . However, the biogas project related with wastes from livestock and poultry breeding developed still rather slowly, reaching merely 15.78 billion $\mathrm{m}^{3}$, from biogas digesters in 2013. This number was only about $25 \%$ of the total biogas potential, even with all raw materials being only from animal excreta, excluding other available materials, like straw. In particular, the biogas potential by excreta produced in large-scale farms could reach about 47.21 billion $\mathrm{m}^{3}$, an amount that is more feasible for the major biogas project (Tian, 2012). Furthermore, this type of biogas project can contribute to ecological restoration, avoiding excessive deforestation and desertification resulting from lack of rural energy. In addition, biogas development could be helpful for curbing air pollution, and also controlling GHG emissions. Livestock excreta-related biogas treatment can reduce $\mathrm{CH}_{4}$ emissions, and can be used to replace coal, further reducing $\mathrm{CO}_{2}$ emissions. This estimated type of energy material consequently could reduce GHG emissions by about 220 million tons of $\mathrm{CO}_{2}$ equivalent in 2013. Hence, development of biogas projects related with animal husbandry has a great potential in rural China. What's more, the gas discharged from burning biogas is of carbon neutrality and no toxic components, such as $\mathrm{NO}_{\mathrm{x}}$ or $\mathrm{SO}_{2}$. The thermal efficiency of $50 \%$ burning biogas for a biogas digester of $8 \mathrm{~m}^{3}$ can provide more than $80 \%$ of a household's daily energy requirements, even under normal rural conditions of northwest China (Ding et al., 2012). It is of profound strategic importance for China's large scale biogas digester application, in response to native rural environment and applied energy, and global climate change.

\section{Discussion}

The pollution driven by livestock and poultry breeding has increasing environmental consequences for the contamination of air, soil and water, as well as for agro-product safety and human health. Moreover, the quantities of livestock and poultry and, accordingly, their wastes may be underestimated, since China's livestock and poultry breeding is mostly characterized by the traditional dispersive small-scale peasant production mode,

Table 4

Panel cointegration test results .

\begin{tabular}{|c|c|c|c|c|c|c|c|}
\hline & Panel v & Panel rho & Panel PP & Panel ADF & Group rho & Group PP & Group ADF \\
\hline No deterministic trend & -3.39 & -0.47 & $-8.22^{* * * b}$ & $-8.28^{* * *}$ & 3.12 & $-7.08^{* * *}$ & $-5.12^{* * *}$ \\
\hline Deterministic intercept and trend & -6.38 & 1.63 & $-8.84^{* * *}$ & $-8.86^{* * *}$ & 4.61 & $-10.99^{* * *}$ & $-7.14^{* * *}$ \\
\hline
\end{tabular}

a Statistics are asymptotically distributed as normal. The variance ratio test is right-sided, while the others are left-sided. For the formulas used in the panel cointegration test statistics, it is described in details in Pedroni $(1997,2004)$.

$\mathrm{b}{ }^{* * *},{ }^{* *}$ and ${ }^{*}$ rejects the null of no cointegration at the $1 \%, 5 \%$ and $10 \%$ level, respectively. 
Table 5

Panel cointegration estimation results by OLS and DOLS.

\begin{tabular}{llllll}
\hline & GDP & GDP & AO & Shape of curve & TP $^{\mathrm{c}}$ \\
\hline OLS & $7.496^{* * *}$ & $-0.459^{* * *}$ & $0.623^{* * *}$ & Inverted U-shaped & 20.4 \\
& 22.309 & -24.776 & 8.552 & & \\
DOLS $^{\text {a }}$ & $2.385^{* * * b}$ & $-0.128^{* * *}$ & $0.341^{* * *}$ & Inverted U-shaped & 51.8 \\
& 5.543 & -4.635 & 6.189 & & \\
\hline
\end{tabular}

a Automatic leads and lags specification are based on AIC criterion.

b ${ }^{* * * * *}$, and ${ }^{*}$ denotes the estimator of a parameter is significant at $1 \%, 5 \%$ and $10 \%$ level, respectively.

c TP denotes tuming point of quadratic curve (thousand Yuan, 2013 CNY).

predominated by the single rural household unit. With rapid economic growth and consumptive change, problems arising from animal husbandry industry can be increasingly great, and there will be many major challenges to address special environment and energy issues in rural China, and also other rural areas of developing countries.

The inverted U-shaped environment-economy nexus indicates that $\mathrm{N}$ may increase at first, and then decline as the economy grows. $\mathrm{N}$ would decrease constantly, when GDP per capita exceeds a critical value in one region. But in other relatively underdeveloped areas, it would increase with income growth in a certain period (see Fig. 3). Compared with the EKC results across various indicators and studies, this value of turning point is much lower than those for agricultural pollutants from application of pesticides and fertilizer, and generally similar to those for pollutants such as $\mathrm{SO}_{2}$ (Brock and Taylor, 2005; Li et al., 2016). The pattern of the EKC relationship in China's animal husbandry wastes may be interpreted as follows:
First, the emerging EKC trend could be the results of increased cleaner production activities that produce less pollution by ecological circular agriculture based on household biogas in some relatively developed regions, along with economic growth (Grossman and Krueger, 1995; Markus, 2002). This effect is more evident in aggregate studies due to the 'compensating effects' (Galeotti et al., 2009). In addition, 'learning by doing' offers several interpretations to the growth-pollution relationship and alters the costs of pollution control (Brock and Taylor, 2005). Second, carrying out strong environmental policies is thought to be one of the most important determinants for the EKC's shape (Magnani, 2001). As early as in 2001, the Discharge Standard of Pollutants from Livestock and Poultry Breeding was roughly implemented, which was difficult to be carried out in remote and backward areas and implemented far more thoroughly in some developed regions, and some special plans for the reduction of animal husbandry pollution were further promulgated by local governments in some developed areas. Third, the transition of economy system and an urban-rural dual structure is the fundamental approach for agriculture-related environmental improvement in China. A more balanced urban-rural economy landscape and rapid urbanization processes is exhibited in some developed areas, wherein the large scale production is one of the main industrial organization patterns of livestock and poultry breeding and wastes can be gradually disposed of through point source pollution treatment and biogas projects.

However, China still have a long way to go for treating pollution from livestock and poultry breeding, especially in the most areas of Central China and West China. The agriculture-environment nexus should be accorded much more importance. Most salient are

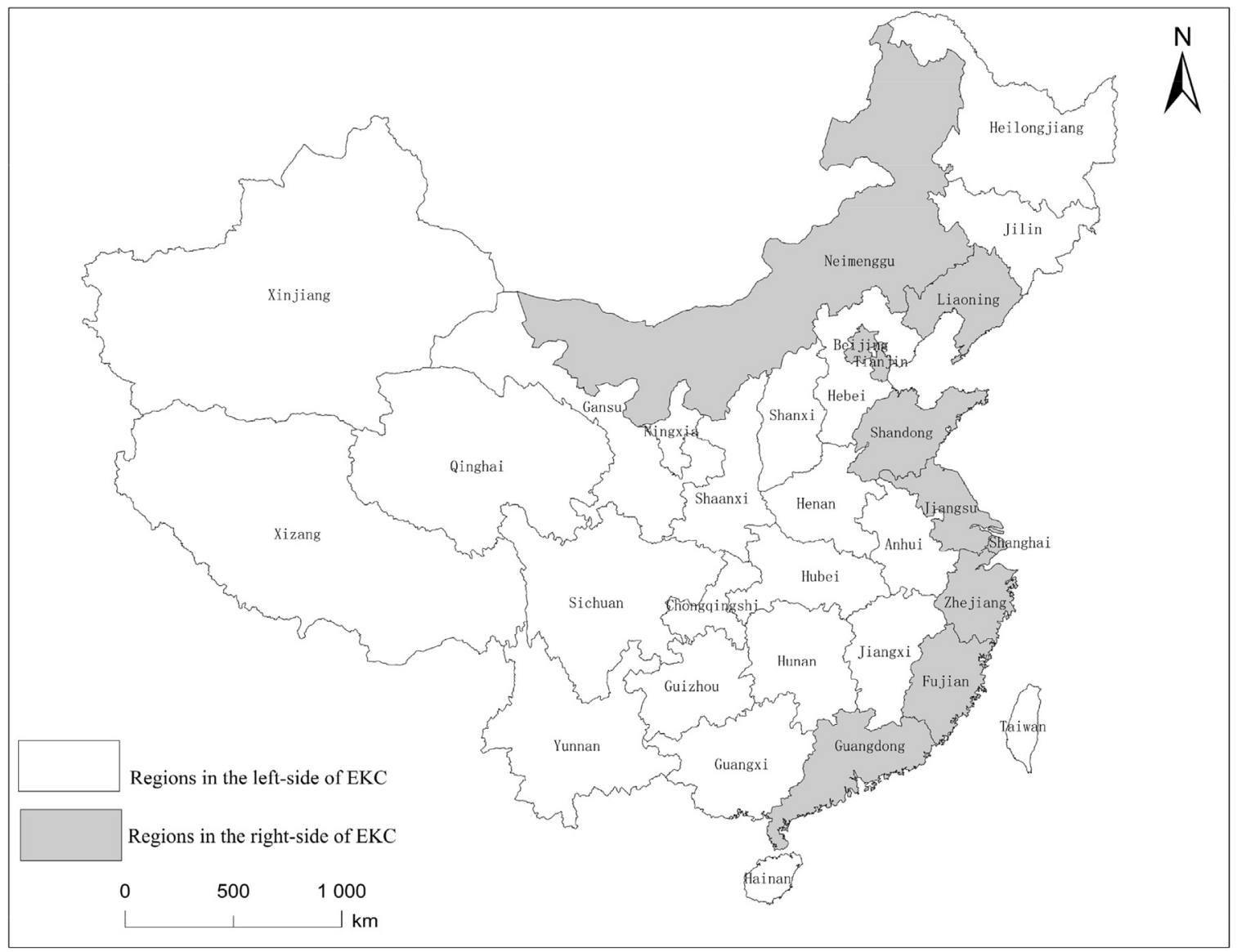

Fig. 3. Spatial pattern related with EKC in China. 
threshold effects, namely that an environmental measure is implemented after the threshold value has been reached. China's present rural production pattern is mostly characterized by the traditional organization based on single small-scale farmer household units, with a series of special rural issues, like the nearly unregulated waste treatment, energy poverty, unbalanced nutrient inputs to the agro-ecosystem and the resulting serious pollution situation, especially in backward rural areas. Due to the long-range urban-rural divided socio-economic system and a strategic agriculture-industry scissor gap, the rural environmental protection and energy security is neglected seriously, significantly indicated in the severe insufficiencies in the capacity of measures, agencies and infrastructure in the rural communities. Some effective rural energy and environment measures have been enforced in metropolitans and industrial areas, but a more discreet approach is required urgently in agriculture and rural areas, especially given the long-standing dual structure, planning mode and the lack of critical cost-benefit incentive mechanism. After all, complicated rural institutional and socioeconomic conditions can be worthy of attention a fortiori in China. In addition, regional development differentiation may result in various spatial and temporal characteristics of environment and energy, with regards to animal husbandry growth in eastern, central and western regions of China. Rural environmental policies and critical technology should thus become diversified and locally customised in terms of characteristics and differences occurring over time and across regions.

It seems one of the most important strategies of environmental improvement is to promote economic growth based on EKC results. However, the estimation of a curve and its turning point can be determined only in accordance with empirical data, and the relationship between agriculture and the environment is complex. Moreover, the EKC results may initially show the same pattern as the inverted U-shaped curve, but this might be only a short-run phenomenon; and beyond a certain income level, it will return to exhibiting a positive relationship between growth and the emission (Brock and Taylor, 2005). This inverted U-shaped relationship does not indicate that environmental degradation is only a temporary phenomenon associated with some stages of economic growth and that environmental degradation will naturally decrease following a certain level of economic growth without enactment of efficient rural energy and environmental measures.

\section{Policy implications and conclusion}

The present study results provide a general picture of animal husbandry related environment-economy nexus and the availability of biogas resources and waste treatment in rural China, which might be helpful to focus and advance the debate on rural environment and energy policies.

The treatment of pollution from livestock and poultry breeding is a complicated task. For this type of energy material located in wrong places, development of biogas digesters would appear to be an ideal policy for waste reduction and sustainable revitalized agriculture by converting animal dung, itself a serious pollutant source for soil and water bodies if discharged into the environment, into a clean and environment-friendly energy source, whilst also preventing excessive chemical fertilizer application via organic fertilizer use. Besides, it has been being dramatically and increasingly thought in various countries including some developing ones, as a complete small-scale household generator pattern offering the effective option to supply electricity and daily energy consumption, especially to remote and undeveloped areas (Dai et al., 2015). Rural biogas energy system should be taken significantly as a national strategy for adapting commercial energy crisis, protecting local environment and mitigating global climate change.
To address rural energy crisis and environmental change issues, and build a 'beautiful countryside' free of the environmental and health concerns posed by untreated animal wastes, a range of renewable energy options has been actively pursued in China, especially over the past 5 years, including support for rural household biogas plants. These efforts received a further additional impetus in the adoption of the National Twelfth Five-Year Plan (2011-2015), which vigorously strives to green China's growth and lower its carbon intensity, including in the rural sector. However, there was only about a $1 \%$ increase of utilized biogas potential in recent years in rural China. Although biogas has long been recognised as a technology offering environmental, economic and health benefits, its uptake was nowhere near commensurate with its potential, and in some areas was even often abandoned only a short while after being adopted.

In China, rural energy and environmental issues are put in charge by many of the central government agencies, including the National Development Reform Commission (NDRC), Ministry of Environmental Protection (MEP) and Ministry of Agriculture (MA) and others. The national energy saving and energy supply strategy is released by NDRC, and the emission reduction and pollution control mission is assigned by MEP, but rural energy and environmental issues are much related with the tasks of MA. Combined with long standing urban-rural dual development mode, most of the central government's energy and environment related policies or programs are focused on urban and industrial sector, supervised by NDRC and MEP (Li et al., 2016). And the main mission of MA is to promote food supply and safety, the energy and environmental issues being overlooked for a long time or not addressed similar to industry considering. It may be one of the possible solutions to put NDRC and MEP in charge of the rural energy supply and environmental protection, and to implement tougher rural enforcement measures, including integrated urban-rural planning strategy. So far a separate document aiming at the rural energy construction has yet not been issued in China. Furthermore, more cost-benefit incentives are needed and market mechanisms have to be improved in order to advance the utilisation of this renewable energy, such as subsidies, taxes and other environmental and energy related market-based stimulus policies, proved to be effective in many rural areas of developed countries globally. It is critical to internalize all the cost of farming behaviours and rural energies, and to subsidize environment-friendly renewable energy modes. Besides, under the largely dispersed smallholder farming and husbandry modes in rural China, data acquisition of rural pollution sources and energy materials, as the first step of energy system research and policymaking, is difficult and need significant resources and time. It is expected that the future basic rural data statistic services will be improved, since the First National Pollution Source Census Bulletin was released in 2010 .

Additionally, the policy implementation of biogas digester is mainly from top to down and through pilot projects, focusing only upon the provincial or central level. Certainly, as it should be, biogas is not suitable for all farmers. The criteria and requirements for successful adoption and operation of biogas include a sufficient number of penned animals, appropriate temperatures and preferably mild winters and adequate financial resources to overcome liquidity constraints and afford the upfront investment. These determinants could be met for many smallholder farmers at present. In short, the rural energy policies should be made down to the district and county and especially rural households, in the meantime analysis on rural households' knowledge and perceptions of renewables with special attention on biogas resources from animal husbandry is essential, with a deeper understanding of strategic importance and basis of resource surveying and planning. Both topdown policies and bottom-up approaches can be indispensable, in 
addition to 'beautiful countryside' propaganda, since the external effects of animal husbandry, its public goods property and especially the small production unit mode could complicate the issue in China. The crux of the matter is to deal with China's serious long standing urban-rural dualistic structure. China should comprehensively address rural energy and environmental needs by fully enlisting government entities, enterprises and farmers, and actively giving farmers more special effective guidelines and motivations for waste management and biogas development related with livestock and poultry breeding, applicable to the specific characteristics of a dispersed small-scale peasant economy. Significantly, a circular ecological agriculture mode, integrating the construction of biogas facilities with efforts to rebuild rural infrastructure sponsored by government, with market mechanisms on popularization of a biogas net, appears to be a prerequisite.

This study provides a general overview of the likely animal husbandry related environmental impacts and energy potential issues in China, which is among the most challenging in the world due to the extent of population and economic activity involved. Although further investigation is clearly needed to answer the question of how best to proceed before any unquestionable conclusion can be drawn, deriving the quantitative estimates such as those presented in this study, is helpful to advance the policy debate in developing countries.

\section{Acknowledgement}

This study was supported by the State Basic Science Key Project of China (No. 2007FY110300), the National Natural Science Foundation of China (No. 41371535, 41301642), Foundation of Ethnic Group Culture Research Base of Nanling Corridor, Key Research Institute of Humanities and Social Sciences in Guangxi General Universities (No. 2015KF03), and the Golda Meir Fellowship. We are also grateful for help from Prof Suocheng Dong, Dr Faith Sternlieb and Dr Dhruba Bijaya G C.

\section{References}

Aftab, A., Hanley, N., Baiocchi, G., 2010. Integrated regulation of non-point pollution: combining managerial controls and economic instruments under multiple environmental targets. Ecol. Econ. 70 (1), 24-33.

Andreoni, J., Levinson, A., 2001. The simple analytics of the environmental Kuznets curve. J. Public Econ. 80 (2), 269-286.

Bouwman, A.F., Beusen, A.H.W., Billen, G., 2009. Human alteration of the global nitrogen and phosphorus soil balances for the period 1970-2050. Glob. Biogeochem. Cycles 23. GBOA04.

Brock, W.A., Taylor, M.S., 2005. Economic growth and the environment: a review of theory and empirics. In: Aghion, P., Durlauf, S. (Eds.), Handbook of Economic Growth, Amsterdam, pp. 1749-1821, 1(28).

Carson, R.T., 2010. The environmental Kuznets curve: seeking empirical regularity and theoretical structure. Rev. Environ. Econ. Policy 4 (1), 3-23.

China Council for International Cooperation on Environment and Development (CCICED), 2009. The energy, environment and climate change adaptation issues during the rural development in China. China council for international cooperation on environment and development policy research report 2009. In Proceedings of the CCICED Annual Conference in 2009, 11.

Chaubey, I., Edwards, D.R., Daniel, T.C., Moore, P.A., Nichols, D.J., 1995. Effectiveness of vegetative filter strips in controlling losses of surface-applied poultry litter constituents. Trans. ASAE 38, 1687-1692.

Chen, M., Chen, J., Sun, F., 2010. Estimating nutrient releases from agriculture in China: an extended substance flow analysis framework and a modeling tool. Sci. Total Environ. 408 (21), 5123-5136.

Chowdhury, R.R., Moran, E.F., 2012. Turning the curve: a critical review of Kuznets approaches. Appl. Geogr. 32, 3-11.

Christiaensen, L., Heltberg, R., 2012. Greening China's Rural Energy: New Insights on the Potential of Smallholder Biogas. Policy Research Working Paper. World Bank. No WPS 6102.

Center for National Agricultural Technology Extension (CNATE), 1999. The Organic Fertilizer Nutrients in China. China Agriculture Press, Beijing (in Chinese).

Copeland, B.R., Taylor, M.S., 2004. Trade, growth and the environment. J. Econ. Lit. $42(1), 7-71$
Dai, J., Chen, B., Hayat, T., Alsaedi, A., Ahma, B., 2015. Sustainability-based economic and ecological evaluation of a rural biogas-linked agro-ecosystem. Renew. Sustain. Energy Rev. 41, 347-355.

Dasgupta, S., Laplante, B., Wang, H., Wheeler, D., 2002. Confronting the environmental Kuznets curve. J. Econ. Perspect. 16, 147-168.

de Ribeiro, F.M., Kruglianskas, I., 2015. Principles of environmental regulatory quality: a synthesis from literature review. J. Clean. Prod. 96, 58-76.

Department for Environment Food and Rural Affairs (DEFRA), 2004. Mapping the Problem: Risks of Diffuse Water Pollution from Agriculture. DEFRA, London.

Dinda, S., 2004. Environmental Kuznets curve hypothesis: a survey. Ecol. Econ. 49 (4), 431-455.

Ding, W.G., Niu, H.W., Chen, J.S., Du, J., Wu, Y., 2012. Influence of household biogas digester use on household energy consumption in a semi-arid rural region of northwest China. Appl. Energy 97, 16-23.

European Environment Agency (EEA), 2005. Source Apportionment of Nitrogen and Phosphorus Inputs into the Aquatic Environment (No.7/2005) (Copenhagen, EEA).

Fan, J., Liang, Y.T., Tao, A.J., Sheng, K., Ma, H.L., Xu, Y., Wang, C.S., Sun, W., 2011. Energy policies for sustainable livelihoods and sustainable development of poor areas in China. Energy Policy 39 (3), 1200-1212.

Galeotti, M., Manera, M., Lanza, A., 2009. On the robustness of robustness checks of the Environmental Kuznets Curve hypothesis. Environ. Resour. Econ. 42 (4), $551-574$.

Galloway, J.N., Aber, J.D., Erisman, J.W., Seitzinger, S.P., Howarth, R.W., Cowling, E.B., Cosby, B.J., 2003. The nitrogen cascade. Bioscience 53, 341-356.

Gao, D., Chen, T.B., Liu, B., Zheng, Y.M., Zheng, G.D., Li, Y.X., 2006. Releases of pollutants from poultry manure in China and recommended strategies for the pollution prevention. Geogr. Res. 125 (12), 311-319 (in Chinese with English abstract).

Gerber, P., Chilonda, P., Franceschinim, G., Menzim, H., 2005. Geographical determinants and environmental implications of livestock production intensification in Asia. Bioresour. Technol. 96 (2), 263-276.

Grossman, G., Krueger, A.B., 1991. Environmental Impact of North American Free Trade Agreement. NBER Working Paper. No. 3914.

Grossman, G., Krueger, A.B., 1995. Economic growth and the environment. Q. J. Econ. 110 (2), 353-377.

Hao, Y., Liu, Y.M., 2016. The influential factors of urban PM2.5 concentrations in China: a spatial econometric analysis. J. Clean. Prod. 112, 1443-1453.

Im, K.S., Pesaran, M.H., Shin, Y., 2003. Testing for unit roots in heterogeneous panels. J. Econ. 115 (1), 53-74.

International energy agency (IEA)/Organization for Economic Co-operation and Development (OECD), 2013. World Energy Outlook 2013. International Energy Agency, Paris, France.

Israel, D., Levinson, A., 2004. Willingness to Pay for Environmental Quality: Testable Empirical Implications of the Growth and Environment Literature. Contributions to Economic Analysis and Policy. Berkeley Electronic Press, 3(1).

Jin, X.C., 1995. Lacustrine Environment. China Ocean Press, Beijing (in Chinese)

Jones, L.E., Manuelli, R.E., 2001. Endogenous policy choice: the case of pollution and growth. Rev. Econ. Dyn. 4, 369-405.

Kaika, D., Zervas, E., 2013. The environmental Kuznets curve (EKC) theory. Part B: critical issues. Energy Policy 62, 1403-1411.

Kao, C., Chiang, M.H., 2000. On the estimation and inference of a cointegrated regression in panel data. In: Baltagi, B.H. (Ed.), Advances in Econometrics. Nonstationary Panels, Panel Cointegration and Dynamic Panels. JAI Press, Amsterdam.

Katz, D., 2015. Water use and economic growth: reconsidering the Environmental Kuznets Curve relationship. J. Clean. Prod. 88, 205-213.

Levin, A., Lin, C., Chu, C., 2002. Unit root tests in panel data: asymptotic and finitesample properties. J. Econ. 108 (1), 1-24.

Li, C.B., He, L.N., Cao, Y.J., Xiao, G.X., Zhang, W., Liu, X.H., Yu, Z.C., Tan, Y., Zhou, J.J., 2014. Carbon emission reduction potential of rural energy in China. Renew. Sustain. Energy Rev. 29, 254-262.

Li, F., Dong, S.C., Li, F.J., Yang, L.B., 2016. Is there an inverted U-shaped curve? Empirical analysis of the Environmental Kuznets Curve in agrochemicals. Front. Environ. Sci. Eng. 10 (2), 276-287.

MacDonald, G.K., Bennett, E.M., Potter, P.A., Ramankutty, N., 2011. Agronomic phosphorus imbalances across the world's croplands. PNAS 108, 3086-3091.

Maddala, G.S., Wu, S., 1999. Comparative study of unit root tests with panel data and a new simple test. Oxf. Bull. Econ. Stat. 61, 631-652.

Magnani, E., 2001. The Environmental Kuznets Curve: development path or policy results. Environ. Model. Softw. 16 (2), 157-165.

Mallin, M.A., Cahoon, L.B., 2003. Industrialized animal production: a major source of nutrient and microbial pollution to aquatic ecosystems. Popul. Environ. 24 (5), $369-385$.

Managi, S., 2006. Are there increasing returns to pollution abatement? Empirical analytics of the Environmental Kuznets Curve in pesticides. Ecol. Econ. 58 (3), 617-636.

Markus, P., 2002. Technical progress, structural change and the environmental Kuznets curve. Ecol. Econ. 2 (3), 381-389.

McCoskey, S., Kao, C., 1999. Comparing Panel Data Cointegration Tests with an Application of the Twin Deficits Problem. Working Paper. Center for Policy Research, Syracuse University.

McCoskey, S., Kao, C., 2001. A Monte Carlo comparison of tests for cointegration in panel data. J. Propag. Probab. Stat. 1 (2), 165-198. 
Ministry of Environmental Protection (MEP), 2010. National Bureau of Statistics (NBS), Ministry of Agriculture (MA), P. R. China. First National Pollution Source Census Bulletin (in Chinese). http://www.zhb.gov.cn/gkml/hbb/bgg/201002. pdf.

National Bureau of Statistics (NBS), 2011. Ministry of Environmental Protection (MEP), P. R. China. China Statistical Yearbook on Environment. China Statistics Press, Beijing (in Chinese).

Panayotou, T., 1993. Empirical Tests and Policy Analysis of Environmental Degradation at Different Stages of Economic Development. Working Paper. International Labor Office, Technology and Employment Programme.

Pedroni, P., 1997. Panel Cointegration: Asymptotic and Finite Sample Properties of Pooled Time Series Tests, with an Application to the PPP Hypothesis: New Results. Working Paper in Economics. Indiana University.

Pedroni, P., 2000. Fully modified OLS for heterogeneous cointegrated panels. In: Baltagi, B.H. (Ed.), Advances in Econometrics. Nonstationary Panels, Panel Cointegration and Dynamic Panels. JAI Press, Amsterdam.

Pedroni, P., 2004. Panel cointegration: asymptotic and finite sample properties of pooled time series tests with an application to the PPP hypothesis. Econ. Theory 20, 597-625.

Qu, H., 2007. Compensation Theory and Approach for Controlling of Agricultural Non-point Source Pollution. Doctoral Dissertation. Chinese Academy of Agricultural Sciences (in Chinese with English abstract).

Rodriguez, H.G., Popp, J., Gbur, E., Chaubey, I., 2011. Environmental and economic impacts of reducing total phosphorous runoff in an agricultural watershed. Agric. Syst. 104, 623-633.

Schipanski, M.E., Bennett, E.M., 2012. The influence of agricultural trade and livestock production on the global phosphorus cycle. Ecosystems 15, 256-268.

State Council Information Office of China (SCIO), 2007. China's Energy Conditions and Policies (in Chinese). http://www.china.org.cn/english/environment/ 236955.htm.

State Environmental Protection Administration (SEPA), 2002. Investigation of National Livestock and Poultry Pollution and Countermeasures. China Environmental Science Press, Beijing (in Chinese).

Shortle, J.S., Abler, D., 2001. Environmental Policies for Agricultural Pollution Control. CAB International Publishing, New York.

Song, L., Deng, L.W., Yin, Y., 2010. Biogas production potential and characteristics of manure of sheep, duck and rabbit under anaerobic digestion. Trans. Chin. Soc. Agric. Eng. 26 (10), 277-282 (in Chinese with English abstract).

Stern, D.I., 2003. The Environmental Kuznets Curve. Internet Encyclopedia of Ecological Economics, International Society for Ecological Economics. Available at: http://isecoeco.org/pdf/stern.pdf.
Stern, D.I., 2004. The rise and fall of the environmental Kuznets curve. World Dev $32,1419-1439$.

Stern, D.I., 2010. Between estimates of the emissions-income elasticity. Ecol. Econ. 69 (11), 2173-2182.

Stokey, N.L., 1998. Are there limits to growth? Int. Econ. Rev. 39 (1), 1-31.

Tian, Y.S., 2012. Potential assessment on biogas production by using livestock manure of large-scale farm in China. Trans. Chin. Soc. Agric. Eng. 28 (8), 230-234 (in Chinese with English abstract).

Townsend, A.R., Howarth, R.W., Bazzaz, F.A., Booth, M.S., Cleveland, C.C., Collinge, S.K., Dobson, A.P., Epstein, P.R., Keeney, D.R., Mallin, M.A., Rogers, C.A., Wayne, P., Wolfe, A.H., 2003. Human health effects of a changing global nitrogen cycle. Front. Ecol. Environ. 1 (5), 240-246.

Unruh, G.C., Moomaw, W.R., 1998. An alternative analysis of apparent EKC-type transitions. Ecol. Econ. 25, 221-229.

United States Environmental Protection Agency (USEPA), 2009. National Water Quality Inventory. USEPA, Washington D C.

Vitousek, P.M., Aber, J.D., Howarth, R.W., Likens, G.E., Matson, P.A., Schindler, D.W. Schlesinger, W.H., Tilman, D.G., 1997. Human alteration of the global nitrogen cycle: sources and consequences. Ecol. Appl. 7, 737-750.

Wang, Q., Chen, H.D., Wang, H., 2011. A study on the total quantity control of regional livestock rising: based on the N/P capacity of land. Chin. Agric. Sci. Bull. 27 (3), 279-284 (in Chinese with English Abstract).

Wang, Y., Zhang, X., Kubota, J., Zhu, X.D., Lu, G.F., 2015. A semi-parametric panel data analysis on the urbanization-carbon emissions nexus for OECD countries. Renew. Sustain. Energy Rev. 48, 704-709.

Wang, Y., Chen, L., Kubota, J., 2016a. The relationship between urbanization, energy use and carbon emissions: evidence from a panel of Association of Southeast Asian Nations (ASEAN) countries. J. Clean. Prod. 112, 1368-1374.

Wang, Y., Han, R., Kubota, J., 2016b. Is there an Environmental Kuznets Curve for $\mathrm{SO}_{2}$ emissions? a semi-parametric panel data analysis for China. Renew. Sustain. Energy Rev. 54, 1182-1188.

Xu, B., Lin, B.Q., 2015. Factors affecting carbon dioxide $\left(\mathrm{CO}_{2}\right)$ emissions in China's transport sector: a dynamic nonparametric additive regression model. J. Clean. Prod. 101, 311-322.

Yao, L., Liu, J.R., Zhou, T., Wang, R.S., 2016. An analysis of the driving forces behind pollutant emission reduction in Chinese industry. J. Clean. Prod. 112 1395-1400.

Zhang, C.L., Yang, G.H., Ren, G.X., 2008. Effects of temperature on biogas production efficiency and fermentation time of four manures. Trans. Chin. Soc. Agric. Eng. 24 (7), 209-212 (in Chinese with English abstract). 